male). Their mean age was $70.63 \pm 10.60$ years (range, $46-96$ years). The description of the causes of fracture, its level, the access route and the cement leaks are expressed in TABLE. The median time from fracture to vertebroplasty was 3 months [1-6]. $78 \%$ of the fractures were osteoporotic and had a better response to pain at 6 months than all other fractures $(p<0.05)$, although at 12 months there were no differences $(p=0.42)$. Only $12.5 \%$ had refracture. Pain control and vertebral refracture did not differ between neither the access rout nor the cement leakage and its magnitude. In the 12-month follow-up, 7 patients died (6 due to neoplasia, 1 due to sudden death) and no case was related to vertebroplasty.

Conclusions: In our experience vertebroplasty has been shown to be an effective technique for the control of refractory pain in vertebral fractures regardless of cause and time of evolution. Likewise, only $12.5 \%$ presented refracture in the following 12 months to the procedure. According to our study we can consider vertebroplasty as an effective and safe alternative in this type of patients.

Disclosure of Interest: None declared

DOI: 10.1136/annrheumdis-2017-eular.3543

\section{SAT0601 TREATMENT OF CARPAL TUNNEL SYNDROME (CTS) WITH ESWT: A SHAM CONTROLLED DOUBLE BLINDED RANDOMISED STUDY}

Ö. Karataş ${ }^{1}$, S. Catal ${ }^{2}$, E.A. Gökmen ${ }^{3}$, N. Samanci ${ }^{4} \cdot{ }^{1}$ Physical Medicine and Rehabilitation, Korkuteli Public Hospital; ${ }^{2}$ Physical Medicine and Rehabilitation, Akdeniz University School of Medicine; ${ }^{3}$ Physical Medicine and Rehabilitation, Antalya Training and Research Hospita; ${ }^{4}$ Physical Medicine and Rehabilitation, Akdeniz University School of Medicine, Antalya, Turkey

Background: The carpal tunnel syndrome (CTS) is the most common neuropathy (1). The etiology isn't properly known, but CTS is produced by the chronic compression of median nerve while passing through carpal canal can be associated with this disease (2).

Objectives: The aim of this study was to investigate the efficiency of extracorporeal shockwave therapy (ESWT) in the treatment of CTS.

Methods: 49 hand with the diagnosis of CTS were included in the study. Patients were randomised in ESWT ( $n=29$ hands) and sham ( $n=20$ hands) groups. Patients were randomly allocated to receive 1 session per week for 3 weeks of either sham or active ESWT. All patients were prescribed with tendon and nerve gliding exercises and hand-wrist splint which used night. Patients were evaluated before the treatment, and at the end of the first week, first month and third month after the last ESWT treatment session with Boston Scale (symptom severity and functional capacity), Visual Analogue Scale (VAS) for pain and paresthesia assessment, for muscle strength hand gross grasp and electroneurophysiological parameters.

Results: A total of 38 patients completed the study with 29 wrists in active ESWT and 20 wrists in sham ESWT groups. Groups were similar in age, sex, duration of symptoms, hand gross grasp and electrodiagnostic parameters $(P>0.05)$. In both groups, significant improvements were observed in VAS, Boston Scale and hand gross grasp after treatment. In both groups, there was no statistically significant improvement in electromyographic variables after treatment $(p>0.05)$. However there was no significiant differrence between two groups in all of clinical and electrodiagnostic parameters.

Conclusions: Although ESWT was effective in symptoms in CTS but this efficacy isn't superior to placebo. Our results indicated that ESWT was effective in pain and clinical variables in CTS. Wider and high-quality studies are needed to further demonstrate the effectiveness of ESWT in treatment of CTS.

References:

[1] Ozturk K, Esenyel CZ, Sonmez M, et al: Comparison of carpal tunnel injection techniques: A cadaver study. Scand J Plast Reconstr Surg Hand Surg 2008:42:300-4.

[2] Gelberman RH, Hergenroeder PT, Hargens AR, Lunborg GN, Akeson WH. The carpal tunnel syndrome. A study of carpal canal pressures. J Bone Joint Surg Am 1981;63:380-3.

Disclosure of Interest: None declared

DOI: 10.1136/annrheumdis-2017-eular.5363

\section{SAT0602 MANAGEMENT OF EPICONDYLITIS WITH SINGLE LOCAL INJECTION OF SODIUM HYALURONATE}

\section{R. Petrella, A. Cogliano, A. Decruze. Western University, London, Canada}

Background: Lateral elbow epicondylitis, also known as tennis elbow, is a common musculoskeletal condition causing pain and functional impairment in daily activities. ${ }^{1}$ It affects between $40-50 \%$ of recreational tennis players at some time. ${ }^{2}$ Sodium Hyaluronate $(\mathrm{SH})$ is a natural biological substance which has proven to be effective to improve pain and function in osteoarthritic patients with low incidence of side effects. ${ }^{3}$ Similarly, the administration of periarticular injections of $\mathrm{SH}$ can be an alternative approach to treat chronic epicondylitis. ${ }^{4}$ Objectives: To evaluate the efficacy and safety of a single periarticular injection with $\mathrm{SH}$ in the treatment of epicondylitis.

Methods: A single-site, and placebo-controlled trial was conducted in patients with chronic epicondylitis. Patients' condition was assessed at baseline and afterwards they were randomized 1:1 to receive a single $2.5 \mathrm{ml}$ injection of $\mathrm{SH}$ (manufactured by Tedec Meiji Farma SA) or placebo (saline) at the point of maximal pain at the lateral epicondyle. Additionally, standard of care (RICE: Rest, Ice, Compression and Elevation) was prescribed to both groups. Efficacy assessments were done at days 30 and 90 and included VAS $(0-10 \mathrm{~cm})$ pain at rest and assessment of grip strength, patient global satisfaction, patient assessment of normal function and physician global assessment of elbow injury (all measured using 5-point categorical scale). Adverse events were recorded for safety purposes.

Results: A total of 60 patients were included and completed the study procedures. Both groups were homogeneous at baseline. A statistically significant reduction from baseline in VAS pain at rest and after grip testing was observed at 30 and 90 days in both treatment groups $(p<0.05)$. Besides, inter-group comparison showed statistically significant differences in favour of $\mathrm{SH}$ group at 30 and 90 days $(p<0.05)$. This was associated with significantly greater grip strength, patient global satisfaction and assessment of normal elbow function in SH group vs placebo $(p<0.05)$. Improvement of elbow injury assessed by the physician was also statistically greater in patients treated with $\mathrm{SH}$ compared to placebo $(p<0.05)$. No adverse events were recorded.

Conclusions: A single local injection of $\mathrm{SH}$ administered to patients with epicondylitis was significantly superior to placebo improving pain at rest and after grip testing, through all the study follow up period. The treatment was highly satisfactory for both physicians and patients and there were no safety concerns.

\section{References:}

[1] Chourasia AO, Buhr KA, Rabago DP, Kijowski R, Lee KS, Ryan MP, GrettieBelling JM, Sesto ME. Relationships between biomechanics, tendon pathology, and function in individuals with lateral epicondylosis. J Orthop Sports Phys Ther. 2013 Jun;43(6):368-78. doi:. 10.2519/jospt.2013.4411.

[2] Taylor SA, Hannafin JA. Evaluation and management of elbow tendinopathy. Sports Health 2012; 4(5): 384-93.

[3] Bannuru RR, Schmid CH, Kent DM, Vaysbrot EE, Wong JB, McAlindon TE. Comparative Effectiveness of Pharmacologic Interventions for Knee Osteoarthritis: A Systematic Review and Network Meta-analysis. Ann Intern Med 2015; 162(1): 46-54.

[4] Petrella RJ, Cogliano A, Decaria J, Mohamed N, Lee R. Management of tennis elbow with sodium hyaluronate periarticular injections. Sports Med Arthrosc Rehabil Ther Technol 2010; 2:4.

Disclosure of Interest: None declared

DOI: 10.1136/annrheumdis-2017-eular.2986

\section{SAT0603 AN INNOVATIVE TREATMENT MODALITY FOR ACUTE ILIO-TIBIAL BAND SYNDROME IN RUNNERS: LOCAL HYALURONATE + BOTULINUM TOXIN IN A PROSPECTIVE COHORT OF 45 ATHLETES}

\section{R. Petrella, A. Decruze, J. Decaria. Western University, London, Canada}

Background: lliotibial band syndrome (ITBS) is the most common cause of lateral knee pain in runners ${ }^{1}$. It is an overuse injury that results from repetitive friction of the iliotibial band (ITB) over the lateral femoral epicondyle. Initial treatment includes activity modification, nonsteroidal anti-inflammatory medication, taping, stretching exercise and in severe cases, a corticosteroid injection ${ }^{2}$. Treatment of symptoms and return to activity are variable and can be intractable.

Objectives: To evaluate the efficacy and safety on pain and return to activity of a single, local injection of ITBS with combination hyaluronate and Botulinum toxin in 45 runners.

Methods: 45 runners with at least grade 2 ITBS underwent baseline investigations including pain following symptom-limited treadmill running test during which pain was recorded on a visual analogue scale (VAS 0-10) every minute. Runners then had injection in the area where the iliotibial band crosses the lateral femoral condyle with $2.5 \mathrm{ml}$ combination hyaluronate $(750-1300 \mathrm{kDa})$ with $40 \mathrm{U}$ Botulinum toxin. Additionally, standard of care (RICE: Rest, Ice, Compression and Elevation) and stretching was prescribed but participants were instructed not to use NSAIDS or taping. The same pain VAS measures as well as peak exercise time, patient global satisfaction and patient assessment of normal running function (all measured using 5-point categorical scale) were repeated after 2, 7, 14 and 30 days. The primary outcome was peak pain during symptom-limited treadmill running.

Adverse events were recorded for safety purposes.

Results: 45 consecutive runners with acute (within 7 days) ITBS were included and completed the study procedures. A statistically significant reduction from baseline in VAS peak treadmill exercise was observed at all time points $(p<0.05)$. This was associated with significantly longer exercise time at 7, 14 and 30 days. Patient global satisfaction was increased progressively after 7, 14 and 30 days and assessment of normal running function was described in $>75 \%$ at 14 days. No serious adverse were reported. 3 subjects described transient ( $<24$ hours) weakness in knee extension and 2 subjects described mild pain at the time and location of injection.

Conclusions: A single local injection of combination hyaluronate + Botulinum toxin for ITBS in runners improved pain and exercise time with treadmill running by 7 days post treatment and continued to 30 days. This treatment was satisfactory to runners and resulted in few, limited adverse events.

\section{References:}

[1] Louw M, Deary C. The biomechanical variables involved in the aetiology of iliotibial band syndrome in distance runners - A systematic review of the literature. Phys Ther Sport. 2014 Feb;15(1):64-75. 